\title{
Wet peroxide oxidation of phenol over Cerium impregnated Aluminium and Iron- Aluminium Pillared Clays
}

\author{
Nissam Ellias ${ }^{\mathrm{a}, \mathrm{b}}$ and S. Sugunan ${ }^{\mathrm{a}}$ \\ ${ }^{a}$ Department of Applied Chemistry, Cochin University of Science and Technology Cochin-682022, Kerala,India \\ ${ }^{b}$ Depetment of Chemistry, MES college Mampad,Malappuram-676542,Kerala,India
}

\section{Introduction.}

Hydroxylation of phenol to dihydroxy products is an industrially important reaction as the products found immense application in various fields. The products, hydroquinone and catechol have been used in large scale as photographic film developer, antioxidant, polymerization inhibitor and used as synthetic intermediate for the production of medicines, perfumes etc [1] . The quinone derivatives play an important role in biosystems and find many miscellaneous industrial applications. More over phenol is considered as one of the most toxic water pollutants, harmful to human health and to water life [2,6]. It is classified as a teratogenic and carcinogenic agent listed in water hazard class two in several countries. Hydroxyl radicals have been effectively applied in the field of environmental remediation of pollutants because of their strong oxidation potential capable of degrading wide range of products. Different Advanced Oxidation Processes (AOPs) have been used to generate the $\cdot \mathrm{OH}$ radicals. Among them, the classic Fenton and Fenton-like reagents which contain $\mathrm{Fe}(\mathrm{II})$ or $\mathrm{Fe}$ (III) in combination with $\mathrm{H}_{2} \mathrm{O}_{2}$ remain attractive alternatives for the treatment of non biodegradable contaminants such as phenol [3-6]. However, these systems are seriously affected by the typical drawback of homogeneous catalysis such as separation, regeneration and also by ineffective consumption of oxidant $\mathrm{H}_{2} \mathrm{O}_{2}$. Thus, different Fenton-like heterogeneous catalysts have been developed by immobilizing transition metal cations on adequate supports such as silica, zeolites, pillared clays, activated carbon, polymers, resins etc

Fe-containing molecular sieves, such as Fe-containing zeolite ,Fe-ZSM-5[7] ferrisilicate [8], Fecontaining mesoporous silica such as Fe-MCM-41 [8],Fe-MCM-48 [10] ,Fe-SBA-15[11], $\mathrm{Fe}_{2} \mathrm{O}_{3}$ supported alumina[12] and FeALPO [13] were recently reported in literature which showed high catalytic performance for the oxidation of phenol using $\mathrm{H}_{2} \mathrm{O}_{2}$ as oxidant. Pillared clay containing iron oxide pillars such as Iron pillared clay[14] and mixed pillared clay such as Fe-Al pillared clays[15-18] were successfully employed for the removal of phenolic compounds in water combining good catalytic activity with high stability against iron leaching.

Pillared clays are a class of porous material prepared by the propping apart of natural clay layers by the intercalation of bulky inorganic polyoxo-hydroxo cations followed by the calcinations. The robust metal oxide pillars formed after calcination step increases basal spacing of clays and potential catalytic material with high acidity, surface area and activity were produced [19]. Several process of industrial importance such as friedel's craft alkylation, acylation, oxidations have been reported over pillared clays[20]. Here we report oxidation of phenol over cerium impregnated Aluminiuam and Iron-Aluminium pillared clays in aqueous media. The promoting effect of cerium is also investigated. Our interest was conversion of phenol in to useful product than complete oxidation.

\section{Catalyst preparation.}

\section{Experimental.}

Pillared clays were prepared from Montmorillonite (KSF) clay by ion exchange method.Montmorillonite clay (M) is refluxed with $0.2 \mathrm{M} \mathrm{NaNO}$ solution to produce Na-Montmorillonite $(\mathrm{NaM})$. The pillaring agents of Aluminium and Iron were prepared by the partial hydrolysis of $0.2 \mathrm{M} \mathrm{Al}\left(\mathrm{NO}_{3}\right)_{3}$ and $\mathrm{Fe}\left(\mathrm{NO}_{3}\right)_{3}$ solution respectively by the drop wise addition of $0.4 \mathrm{M} \mathrm{NaOH}$ solution under vigorous stirring $(\mathrm{OH} / \mathrm{M}$ ratio is maintained as 2).The intercalation of pillaring species was done by refluxing aluminium polyoxycation solution to the pre swelled $1 \% \mathrm{Na}$-montmorillonite clay suspension maintained at $80^{\circ} \mathrm{C}$ keeping $\mathrm{Al} / \mathrm{clay}$ ratio $10 \mathrm{mmol} / \mathrm{g}$. The suspension was aged for 24 hours and then filtered and washed and dried at $110^{\circ} \mathrm{C}$ for six hours followed by calcinations at $450^{\circ} \mathrm{C}$ for 4 hours to get the Aluminium Pillared Clay (AlPC). For the preparation of Iron-Aluminium mixed pillared Clay (Fe-AlPC ) aluminium and iron pillaring agents were taken in the molar ratio 5:1 and pillaring agents were added to the clay suspension maintained at $90^{\circ} \mathrm{C}$ and the remaining procedure was done as same above. Cerium is loaded in pillared clay by wet impregnation method. Required amount of cerium nitrate is dissolved in water. It was then added to the calcined pillared clay and stirred for six hours. The water was then evaporated off by maintaining the mixture at $70^{\circ} \mathrm{C}$. The samples then dried at $110^{\circ} \mathrm{C}$ for six hours and finally calcined at $450^{\circ} \mathrm{C}$ for 4 hours to get cerium impregnated pillared 
clay.Cerium impregnated aluminium and iron aluminium pillared clay were denoted as $\mathrm{Ce} / \mathrm{AlPC}$ and $\mathrm{Ce} / \mathrm{Fe}-$ AlPC respectively.

\section{Characterization}

Elemental analyses of the catalyst were done by ICP- AES analysis using GBS plasmalab 8440 instrument. EDX analysis of the catalyst was done in a JOEL JSM-840 with resolution of $1.3 \mathrm{eV}$.XRD analysis of samples were done using Rigaku Dmax Ni filtered $\mathrm{CuK} \alpha$ radiation in 2 to $70^{\circ}$ at a scan rate of $2^{0} / \mathrm{min}$. Surface area and pore volume measurements of catalysts were simultaneously done by Micrometrics Tristar 3000 using $\mathrm{N}_{2}$ gas adsorption/desorption at $77 \mathrm{~K}$ and by the application of BET equation. Samples were activated at $90^{\circ} \mathrm{C}$ for 30 minutes and then degassed at $300^{\circ} \mathrm{C}$ for three hours. FTIR spectra of the samples were recorded using JASCO FT-IR spectrometer using $\mathrm{KBr}$ pellets in the range of $400-4000 \mathrm{~cm}^{-1}$ in the transmission mode. TG analysis were done by Perkin Elmer Pyris Diamond TGA-DTA analyzer with dried samples in nitrogen atmosphere with a heating rate of $10^{\circ} \mathrm{C} / \mathrm{min}$. UV-Vis DR spectra of the prepared samples were taken in 200-800 $\mathrm{nm}$ on Labomed UV-Vis Double beam UVD-500. Acidity and acid site distribution of catalysts were done by Temperature programmed Desorption of Ammonia.TPD of ammonia was done over prepared catalysts as the procedure described below. The pelletized samples are housed in a quartz reactor and preheated in a flow of $\mathrm{N}_{2}$ atmosphere at $300^{\circ} \mathrm{C}$ and cooled to room temperature. Ammonia is injected to the samples and saturated for 30 minutes. The excess physisorbed ammonia was then flushed off. The adsorbed ammonia is desorbed in a programmed manner. The desorbed ammonia is passed through $100 \mathrm{ml} \mathrm{H}_{2} \mathrm{SO}_{4}(0.0125 \mathrm{~N})$ solution. The excess $\mathrm{H}_{2} \mathrm{SO}_{4}$ is back titrated with $\mathrm{NaOH}$ for quantitative determination of acid sites. The amount desorbed at 35$200^{\circ} \mathrm{C}, 200-400^{\circ} \mathrm{C}, 400-600^{\circ} \mathrm{C}$ were assigned as weak, medium and strong acid sites respectively.

The liquid phase hydroxylation of phenol was carried out in a $50 \mathrm{~mL}$ round bottomed flask equipped with air condenser and magnetic stirrer, $0.1 \mathrm{~g}$ of the catalyst was added to calculated amounts of phenol and solvent. Required amounts of $30 \% \mathrm{H}_{2} \mathrm{O}_{2}$ were added drop wise to the reaction medium and reaction ensued at specified temperature. The products were analyzed using Chemito 8610 Gas Chromatograph equipped with flame ionization detector and OV-17 column. Quantitative estimation of tarry products was not pursued and conversion of phenol refers conversion to dihydroxy phenols. Thus the percent conversion (wt $\%$ ) of phenol is the total percentage of phenol transformed in to diphenols.

\section{Result and discussion}

\subsection{Elemental Analysis}

The results of Elemental analysis of the catalysts are given in table 1. It can be seen that appreciable amount of metal is incorporated as metal oxide during the pillaring process. Initial clay have $20.74 \%$ weight as aluminum. After the aluminium pillaring it is increased to 35.8. In Iron- Aluminium pillared clay the weight $\%$ of aluminium and iron are 30.5 and 16.52 respectively. The weight $\%$ of cerium is calculated from EDX analysis. The weight \% of cerium in Ce/AlPC and in Ce/Fe-AlPC is found to be 1.82 and 1.65 respectively. The EDX spectrum of $\mathrm{Ce} / \mathrm{Fe}-\mathrm{AlPC}$ is given in Fig.1

Table - 1: Elemental analysis of prepared catalysts

\begin{tabular}{llllllll}
\hline Catalyst & $\mathbf{S i O}_{\mathbf{2}}$ & $\mathbf{A l}_{\mathbf{2}} \mathbf{O}_{\mathbf{3}}$ & $\mathbf{F e}_{\mathbf{2}} \mathbf{O}_{\mathbf{3}}$ & $\mathbf{N a}_{\mathbf{2}} \mathbf{O}$ & $\mathbf{K}_{\mathbf{2}} \mathbf{O}$ & $\mathbf{M g O}$ & $\mathbf{C a O}$ \\
\hline M & 56.47 & 20.74 & 12.10 & 2.67 & 2.81 & 2.61 & 2.60 \\
NaM & 55.44 & 19.52 & 11.88 & 7.58 & 2.48 & 2.64 & 0.46 \\
AlPC & 47.92 & 35.8 & 11.16 & 0.45 & 1.93 & 2.1 & 0.87 \\
FeAIPC & 47.58 & 30.5 & 16.52 & 0.36 & 2.07 & 2.17 & 0.80 \\
\hline
\end{tabular}

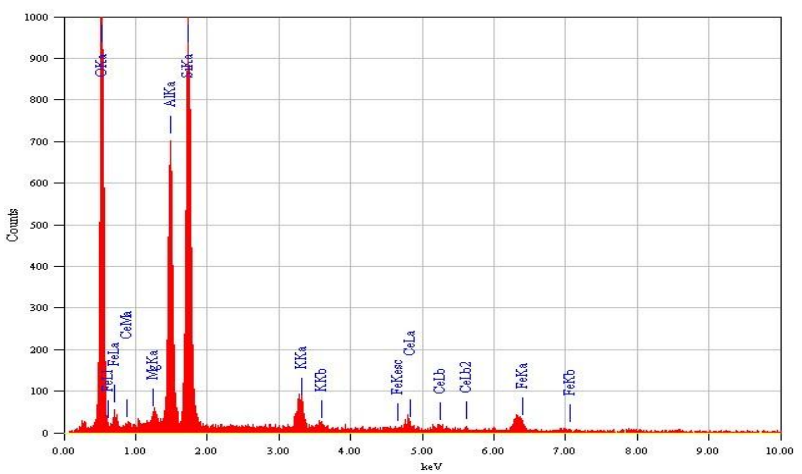

Fig: 1 EDX spectrum of Ce/Fe-AlPC 


\subsection{XRD}

The broad bands obtained in the XRD spectrum instead of sharp peaks can be attributed the semi crystalline nature of clays. The success of pillaring process can readily understood from XRD analysis. The XRD pattern of pillared clays are shown in Fig 2.The parent clay shows peak at $2 \theta$ value 8.9 corresponds to the basal (001)spacing of $9.8 \mathrm{~A}^{0}$. After the pillaring process this value is shifted to lower $2 \theta$ values which indicate the increase in basal spacing of clay by the expansion of clay due the incorporation of metal oxide pillars in between clay layers. The $\mathrm{d}$ spacing was shifted to $19.2 \mathrm{~A}^{0}$ for Aluminium pillared clay and it was shifted to 21.5 $\mathrm{A}^{0}$ for Iron-Aluminium pillared clay' Bergaya et al [21] reported the formation of mixed $\mathrm{Al}_{13-\mathrm{x}} \mathrm{Fe}_{\mathrm{x}}$ pillars, based on the Fe content of the pillared solids. The wide angle XRD patterns of catalysts are given in Fig 3. Peaks at 2 $\Theta$ value 19.6 and 35.1 corresponds to the reflection from (110) and (130) planes respectively of 2:1 phyllosilicate clay. The peak at 26.7 corresponds to quartz impurity. The absence of peaks corresponds to cerium indicate that cerium is uniformly distributed on catalyst surface.

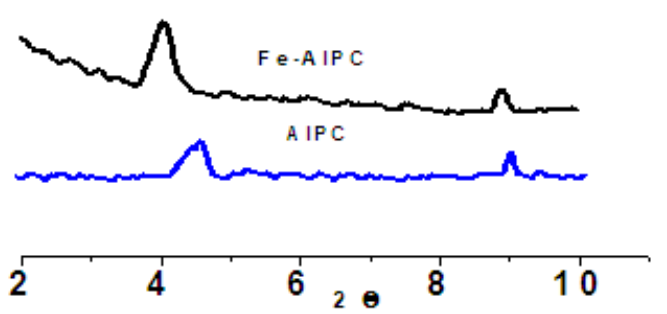

Fig 2 : XRD Of Pillared clays

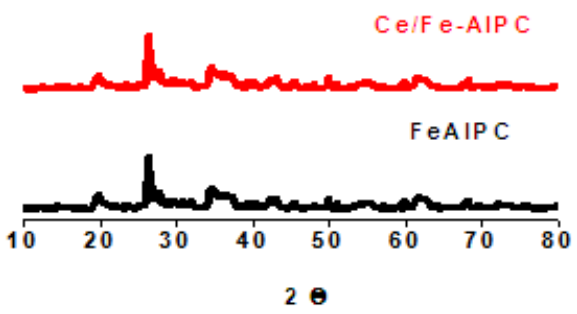

Fig 3: Wide angle XRD of Pillared clays

\subsection{Surface area measurements}

The surface area and pore volume of catalysts are given on the table 2 . The starting parent clay has a lower surface area of $17 \mathrm{~m}^{2} / \mathrm{g}$ only. The increase in surface area of in sodium montmorillonite is attributed to the dealumination of octahedral alumminium during exchange process which may present in interlayer region. As result of pillaring, surface area and pore volume increased drastically since metal oxide pillars are inserted in between the two dimensional gallery of clay layers to produce a three dimensional porous network. The active surface of clays is now more accessible. In cerium impregnated Aluminium pillared clay the surface area is lowered due to pore blocking. But the surface area of Ce/Fe-AlPC is higher than that of Fe-AlPC. This may be due to the additional surface area provided by ceria mesopores.

Table 2: Textural and acidic properties of catalysts.

\begin{tabular}{lllllll}
\hline Catalysts & $\begin{array}{l}\text { Surface Area } \\
\left(\mathrm{m}^{2} / \mathrm{g}\right) \mathrm{S}_{\mathrm{BET}}\end{array}$ & $\begin{array}{l}\text { Pore volume } \\
(\mathrm{cc} / \mathrm{g})\end{array}$ & $\begin{array}{l}\text { Weak } \\
(\mathrm{mmol} / \mathrm{g})\end{array}$ & $\begin{array}{l}\text { Medium } \\
(\mathrm{mmol} / \mathrm{g})\end{array}$ & $\begin{array}{l}\text { Strong } \\
(\mathrm{mmol} / \mathrm{g})\end{array}$ & $\begin{array}{l}\text { Cumulative } \\
(\mathrm{mmol} / \mathrm{g})\end{array}$ \\
\hline NaM & 70 & 0.0253 & 0.249 & 0.137 & 0.034 & 0.420 \\
AlPC & 128 & 0.1689 & 0.443 & 0.308 & 0.132 & 0.883 \\
Fe-AlPC & 132 & 0.1713 & 0.383 & 0.265 & 0.103 & 0.751 \\
Ce/AlPC & 119 & 0.1582 & 0.416 & 0.342 & 0.148 & 0.906 \\
Ce/Fe-AlPC & 143 & 0.1728 & 0.368 & 0.293 & 0.108 & 0.769 \\
\hline
\end{tabular}

The adsorption isotherms of pillared clays are shown in Figs $4 \& 5$. The adsorption isotherm is both the blend of type1 and and Type IV with hysterisis loop H4 (according to IUPAC) characteristics of mesoporous materials with some microspores containing slit like pores. At lower $\mathrm{P} / \mathrm{P}_{0}$ value the shape is of type $\mathrm{I}$ characteristics of microporous material. But at higher $\mathrm{P} / \mathrm{P}_{0}$ values it shows hysteresis loop due to the capillary condensation.

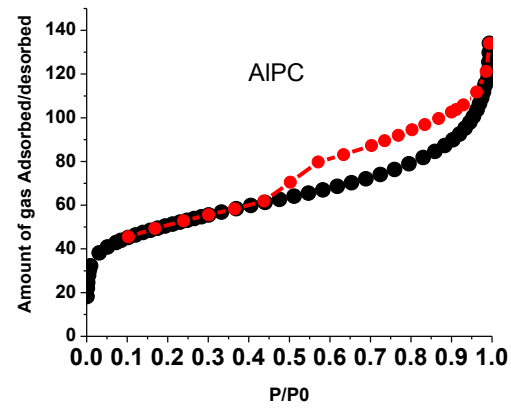

Fig 4: Adsorption isotherm of AIPC

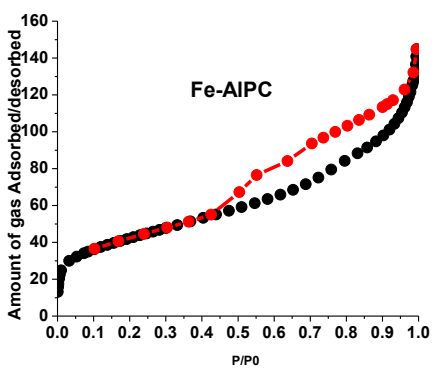

Fig 5: Adsorption isotherm of Fe- AlPC 


\subsection{Acidity measurements}

The results of acidity measurements using TPD of ammonia are given in Table 2.As a result of pillaring a dramatic increase in acidity in weak, medium and strong acidic region is observed. During the pillaring process the desegregation of clay layer helps in exposing more number of acidic sites and the expansion in layer structure in pillared clays increases the accessibility of interlayer protons which otherwise obscure to reactant molecules in parent clay due to smaller interlayer distance. In addition metal oxide pillars formed in the interlayer can contribute to the overall acidity of pillared material. Up on cerium loading the medium and strong acid sites were increased at the expense of weak acid sites.

\subsection{FT-IR Analysis}

Fig 6. shows the infrared (IR) spectra of sodium Montmorillonite and pillared samples. Broad band near 3500 $\mathrm{cm}^{-1}$ corresponds to the stretching vibration of -OH group. For Sodium montmorillonite, this was a very intense peak. The intensity of this peak considerably reduced for the pillared samples showing the loss of hydroxyl groups upon pillaring during calcination at higher temperature.

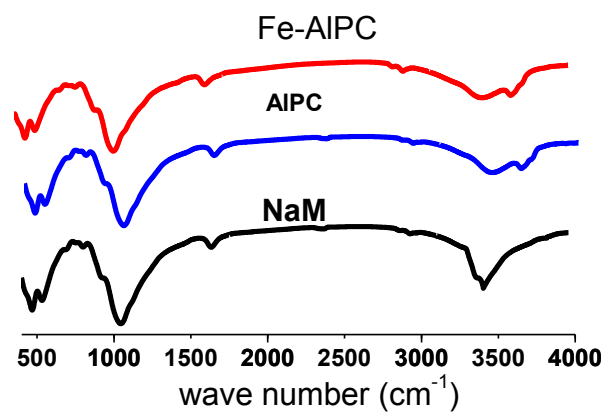

Fig 6: IR spectrum of catalysts

For the pillared samples two bands were observed corresponding to the hydroxyl groups. One probably assigned to the pillar $\mathrm{OH}$ group and the other assigned to layer hydroxyl groups. Peak at around $1600 \mathrm{~cm}^{-1}$ is due to bending vibrations of water. The decrease in the intensity of $-\mathrm{OH}$ peaks is observed after the pillaring process as the pillaring process replaces a large amount of interlayer cations that generally exists as hydrated forms . The band around $1060 \mathrm{~cm}^{-1}$ is due to asymmetric stretching vibrations of $\mathrm{SiO}_{2}$ tetrahedra. A band around $800 \mathrm{~cm}^{-1}$ is due to stretching vibrations of Al tetrahedra and absorption at $526-471 \mathrm{~cm}^{-1}$ is due to bending vibration of $\mathrm{Si}-\mathrm{O}$ [22].

\subsection{Thermogravimetric Analysis.}

The heat changes associated with the preparation process and the thermal stability of the prepared catalysts can be understood from thermo gravimetric analysis(Fig 7). The weight loss up to $200^{\circ} \mathrm{C}$ corresponds to the loss of physisorbed water. The weight loss above $200^{\circ} \mathrm{C}$ in sodium montmorillonite is as result of removal of water originates from dehydration of the layers . This structural collapse continues up to $800^{\circ} \mathrm{C}$.

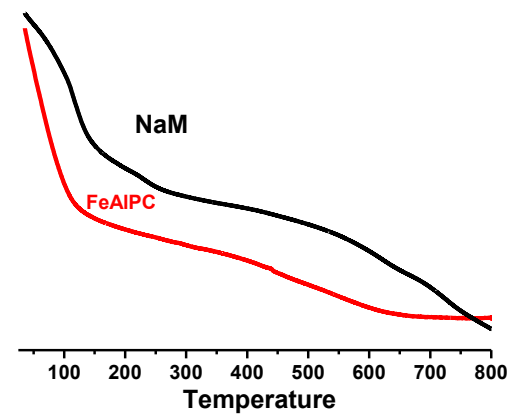

Fig 7: TG profile of NaM and FeAIPC

In intercalated samples the weight loss from $200^{\circ} \mathrm{C}$ to $400^{\circ} \mathrm{C}$ is due to the water removal from the surface, micro pores and the dehydroxylation of hydroxy metal oligomer or polymers. The new deflections at 
$400^{\circ} \mathrm{C}$ is due to the transformation of metal hydroxide in to metal oxide pillars . The weight loss above $500^{\circ} \mathrm{C}$ is absent in pillared clays indicate the additional stability due to the pillaring process.

\subsection{UV-VIS DRS analysis}

The UV-VIS DR spectrum of cerium impregnated catalysts are shown in fig 8.For cerium impregnated Iron-Aluminium pillared clay the broad adsorption peak detected in the range of $250-450 \mathrm{~nm}$ is related to $\mathrm{Fe}^{3+} \leftarrow \mathrm{O}^{2-}$ charge transfer[23]. The bands in the region of 300-400nm are characteristics of $\mathrm{Fe}^{3+}$ in octahedral coordination. The peak around $290 \mathrm{~nm}$ corresponds to $\mathrm{Ce}^{4+} \leftarrow \mathrm{O}^{2-}$ charge transfer transitions can be seen in both catalysts [24].

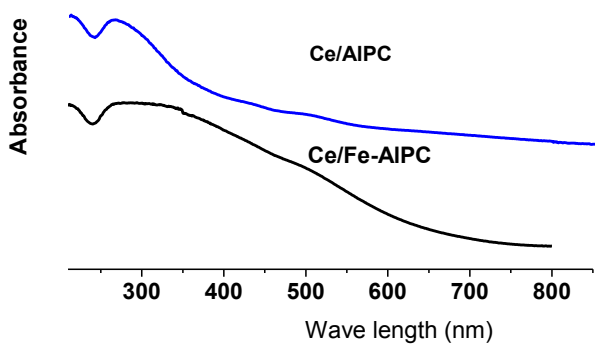

Fig 8: UV DR Spectrum of Ce/AlPC and Ce/Fe-AlPC

\section{Activity studies :-Hydroxylation of phenol}

The hydroxylation of phenol was done over prepared catalysts in aqueous media and the results are given in Table. 3 .As it can be seen, conversion increased to more than two times after the pillaring process. This may be due to increase in surface area, pore volume and acidity after the pillaring process. Phenol hydroxylation is strongly diffusion limited and it was believed that hydroquinone is formed inside the pores and catechol and other products were formed in external surface[25]. Fe-AlPC got higher conversion than AlPC due to higher iron content and higher surface area and pore volume. The incorporation of cerium in pillared clays leads to enhancement in conversion of phenol and selectivity of hydroquinone. Cerium impregnated iron Aluminium pillared clay got more than $80 \%$ conversion of phenol obtained within 45 minutes. This may be due to the promoting effect of ceria, its redox property and additional surface area provided by the ceria mesopores. Prolong reaction time leads to further oxidation of diphenols and tarry products are formed. We limit our study to 45 minnutes and we are interested in converting phenol in to useful products than complete oxidation. Since the reactions are done in aqueous media the prepared catalyst can be effectively used for the abatement of phenol in waste water. Even though there were reports that the conversion depends on acidity, in this present case Iron-Aluminium mixed pillared clay which has less acidity than Aluminium pillared clay have got higher conversion probably due to the higher redox property of iron .

Table 3: Hydroxylation of phenol over various pillared clays

\begin{tabular}{llll}
\hline Catalysts & \multicolumn{2}{c}{ Conversion of phenol } & \multicolumn{2}{c}{ Selectivity } \\
\cline { 3 - 4 } & $(\%)$ & 78.8 & Hydroquinone \\
\hline NaM & 36.2 & 66.6 & 33.4 \\
AlPC & 63.4 & 67.1 & 32.9 \\
Fe-AlPC & 68.8 & 64.3 & 35.7 \\
Ce/AlPC & 72.8 & 60.9 & 39.1 \\
Ce/Fe-AlPC & 82.2 & & \\
\hline
\end{tabular}

Temperature $-70^{0} \mathrm{C}$, phenol :water: $\mathrm{H}_{2} \mathrm{O}_{2}=1: 5: 5$ (volume ratio ), catalyst-100mg, time-45 $\mathrm{min}$

Even though we have not done any mechanistic studies a free radical mechanism can be envisaged as in our earlier reports[18].The suggested mechanism involves the formation of phenoxy radical on catalyst surface, which then reacts with peroxide giving $\mathrm{OH}$ radical and biphenol. The produced free radical propagates the chain by attacking phenol molecule, forming diphenol. 
Fig 9: mechanism of hydroquinone formation with metaloxo peroxide species

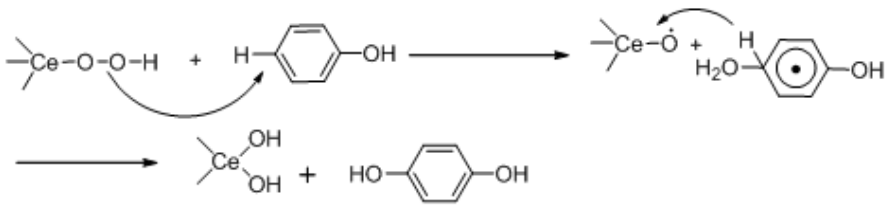

The Fenton type behavior of ceria and the promoting role of cerium in iron based catalysts systems were studied by various researchers [26]. Cerium species played two roles in this model reaction. First, as a widely used promoter in redox reactions, the introduction of ceria could efficiently improve the diphenol distribution. Hydroquinone selectivity is slightly raised after the incorporation of cerium. Cerium forms a metaloxo peroxide species [27] which react with phenol to form hydroquinone rather than catechol as the scheme in figure 9 .

\section{Conclusions}

Aluminium pillared clay and Iron-Aluminium pillared clays were prepared by ion exchange method and cerium was loaded in pillared clays by wet impregnation method. The prepared catalysts were characterized by various physico- chemical methods. The shift in $2 \theta$ value and increase in d spacing indicates the successful pillaring of the clay. The adsorption isotherm of pillared clay is a blend of both type 1 and type IV with hysteresis loop $\mathrm{H} 4$ corresponds to slit like pores characteristics of mesoporous material with some micropores. A large increase in surface area, pore volume and acidity were observed as a result of pillaring. The nature and oxidation state of iron and cerium is confirmed from UV-VIS DRS analysis. The catalytic activities of the prepared catalysts were evaluated for the hydroxylation of phenol in aqueous media. Incorporation of ceria provides promoting effect towards the oxidation of phenol. Cerium impregnated Iron- Aluminium pillared clay is found to be promising catalyst with more than $80 \%$ conversion in 45 minutes owing to redox property and additional surface area provided my ceria mesopres. Incorporation of cerium enhances the selectivity of hydroquinone by the formation of metaloxo peroxide intermediate. These catalysts can be effectively used as green catalyst for the abatement of phenol in waste water.

\section{Acknowledgement}

Financial assistance from KSCSTE and CSIR is gratefully acknowledged

\section{Reference}

[1]. K.Weissermel, H.J. Arpe, Industrial Organic Chemistry, VCH,Weinheim,1993, 358

[2]. ATSDR, 2008. ToxFAQs ${ }^{\mathrm{TM}}$ for Phenol. Agency for Toxic Substances and Disease Registry(ATSDR) (http://www.atsdr.cdc.gov/).

[3]. Fenton H. J. H, J.Chem. Soc,65 ,894, 899

[4]. Hamilton, G. A., Friedman J. P, Campbell P. M, J. Am. Chem. Soc.88, 1966, 266-5268.

[5]. Esplugas. S, Jiménez J, Contreras S., Pascual E., Rodriguez M. Water Res. 36,2002, 1034.

[6]. Busca G, Berardinelli S, Resini C, Arrigí L, J.Hazard. Mater. 160, 2008, 265

[7]. Villa.A. L, CaroCA, Correa C. M , J. Mol. Catal. A: Chem. 228, 2005, 233-240.

[8]. LiB.; Xu, J, Liu, J Zuo, S Pan, Z. Wu ,J. Colloid Interface Sci. 366,2012, , 114-119.

[9]. Choi J, Yoon S, Jang S, AhnW,Catal. Today,73 2006, 280-287.

[10]. ZhaoW,Luo, Y, Deng P, Li Q. Catal. Lett. 73,2001,199-202.

[11]. M. Isabel Pariente ,Fernando Martinez, Juan Antonio Melero, Juan Angel Botas, Applied Catalysis B: Environmental 85 (2008) 24-32

[12]. Carla di Luca, Fernando Ivorra, Paola Massa, and Rosa Fenoglio .Ind. Eng. Chem. Res. 51 2012, 8979-8984

[13]. Xinhong Zhao, Zhongpeng Sun , Zhaoqi ZhuAn Li , Guixian Li , Xiaolai Wang,Catal Lett 143: (2013) ,57-665

[14]. Haithem Bel, Hadjltaief ,Patrick Da Costa, Patricia Beaunier, María Elena Gálvez, Mourad Ben Zina, Applied Clay Science 91-92 (2014) 46-54

[15]. Nihel Ksontini, Wahiba Najjar, Abdelhamid Ghorbel, Journal of Physics and Chemistry of Solids 69 (2008) $1112-1115$

[16]. Nancy Sanabria, Andrea A lvarez, Rafael Molina, Sonia Moreno, Catalysis Today 133-135 (2008) 530-533

[17]. Cezar Catrinescu, Daniela Arsene, Petru Apopei, Carmen Teodosiu, Applied Clay Science 58 (2012) 96-101

[18]. Manju Kurian, S. Sugunan,Chemical Engineering Journal 115 (2006) 139-146

[19]. A.Gil , S.A Korili, R Trujillano and M .A Vicente, Pillared clay and related catalysts, 2010 Springer

[20]. A. Gil, S. A. Korili, and M. A. Vicente, Catalysis Reviews, 50: (2008), 153-221

[21]. F. Bergaya. N. Hassoun, J. Barraoult, L. Gatincau, Clay Miner. 28 (1993) 109

[22]. S.Bodaorado,F Figueras ,Egaarrone .J catal147 (1994)223

[23]. A. Vinu, Dhanshri P. Sawant, K. Ariga, K. Z. Hossain, S.B.Halligudi,M. Hartmann, and M. Nomura.JChem. Mater. 17 2005, 5339-5345

[24]. M. Selvaraj ,D.W. Park,Microporous and Mesoporous Materials 138 (2011)94-101

[25]. A Tuel,S.M Khouzami,YB Taarit ,J .Mol.Catal,68, (1991) 45-52

[26]. Fatma Tomul ,Applied Surface Science 258 (2011) 1836- 1848

[27]. Yanhua Zhang, Fei Gao, Haiqin Wana, Cheng Wu, Yan Kong, Xingcai Wu,Bin Zhao, in Dong, Yi Chen, Microporous and Mesoporous Materials 113 (2008) 393-401 